\title{
Os acordes de Yes we can do vídeo da campanha presidencial de Barak Obama
}

\author{
Philip Tagg (Faculté de Musique, Université de Montreal, Montreal, Canadá) \\ philtagg@sympatico.ca \\ Tradução de Fausto Borém (UFMG, Belo Horizonte, MG) \\ fborem@ufmg.br
}

\begin{abstract}
Resumo: Estudo sobre o loop de quatro acordes \|: Sol Maior - Si Maior - Mi Menor - Dó Maior : \|n na canção Yes we can [Sim, nós podemos] do vídeo de Will.i.am (ADAMS, 2008) lançado durante a campanha presidencial de Barack Obama nos Estados Unidos. A partir da identificação de IOCMs (Materiais Interobjetivos de Comparação) e PMFCs (Campos Paramusicais Conotativos) da análise musemática (TAGG, 2009), compara-se Yes we can com materiais harmônicos, melódicos, ritmicos, de instrumentação e de letras de canções populares da tradição afro-britânico-americana, levando-se também em consideração as atitudes de relevantes compositores e intérpretes populares social e politicamente engajados.

Palavras-chave: Barack Obama, música e política, música e sociedade, análise musemática, harmonia da música popular, intertexto.
\end{abstract}

\section{The Yes we can chords}

Abstract: Study of the four-chord loop $\|: G-B-E m-C:\|$ in the song Yes We Can from the video by Will.i.am (ADAMS, 2008) released during the 2008 US presidential campaign of Barack Obama. Departing from IOCM and PMFC identification of the musematic analysis (TAGG, 2009), Yes We Can is compared to harmony, melody, rhythm, instrumentation and lyrics found in iconic popular songs of the Afro-Bristish-American tradition, also taking into consideration the attitudes of relevant composers and performers engaged in social and political issues.

Keywords: Barack Obama, music and politics, music and society, musematic analysis, popular music harmony, intertext.

\section{1 - Introdução}

Este artigo surgiu como uma simples resposta a uma simples questão enviada por Carol Vernallis à lista online da IASPM (International Association for the Study of Popular Music; veja www.iaspm.net) em Janeiro de 2009. Ela lançou a pergunta: "Alguém já se perguntou sobre a progressão harmônica de Yes we can (Sim, nós podemos), sobre seu conteúdo musical, ou mesmo, sobre as canções populares que ela pode ecoar?". Vernallis estava se referindo ao vídeo de mesmo nome da campanha presidencial de Barak Obama (ADAMS, 2008). ${ }^{1}$ As respostas dos membros da IASPM podem ser sumariadas nos seis pontos descritos a seguir:

(1) Mike Daley e Allan Moore refletiram sobre o potencial do acorde de Si Maior, o progredir harmonicamente "para um lugar inesperado" e o aspecto do "conforto e segurança" relativos da sequência de seu turnaround plagal (2) Allan Moore sugeriu similaridades com progressões de outras gravações, como Jungle (1973) da banda ELECTRIC LIGHT ORCHESTRA (ELO), What becomes of the brokenhearted (1966) de Jimmy RUFFIN e Southern man
(1970) de Neil YOUNG. ${ }^{2}$ (3) Barbara Bradby se referiu à Sitting on the dock of the bay [daqui para frente chamada apenas de Dock of the bay] (1968) de Otis REDDING, numa similaridade intertextual que também foi observada por diversos de meus alunos em Montreal. Ela também observou uma similaridade melódica entre a frase cantada em 0:31 [aos 31 segundos da gravação] de Yes we can no vídeo de Obama e a frase incial "When the night. .." ("Quando a noite. ..") na canção Stand by me (1961) de Ben E. KING. (4) Matthew Bannister apontou similaridades com No woman no cry (1974) de Bob MARLEY e os Wailers e possiveis conotações antêmicas (do inglês anthemic, ou seja, com uma melodia fácil de cantar por muita gente e com o caráter digno ou solene dos hinos [anthems]) em Another girl another planet (1978) da banda de rock norte-americana THE ONLY ONES. (5) Danilo Orozco sugeriu similaridades com matrizes harmônicas de origem espanhola na América Latina. (6) Finalmente, David Uskovich fez referência à canção Don't stop believing (1981) da banda de rock norte-americana Journey. ${ }^{3}$ 
Esta lista de associações intertextuais contribui para um razoável conjunto de IOCMs (Materiais de Comparação Interobjetiva, do inglês Interobjective Comparison Material; veja glossário de termos da análise musemática ao final desse artigo e mais detalhes em www.tagg.org/articles/ptgloss. html\#IOCM), como normalmente aconteceria em um seminário respeitável sobre música popular, no qual a análise musemática está na ordem do dia e no qual todas as referências são relevantes, embora umas mais do que outras.

\section{2 - Os quatro acordes}

Antes de iniciar a análise musemática de Yes we can, gostaria de esclarecer, dentro do possível, sobre as estruturas convencionais da progressão harmônica com a qual estamos lidando. Assim como meus colegas da IASPM, escutei o loop de quatro acordes que ocupa quatro compassos quaternários $\|: G-B-E m-C:\|$ ou, em termos relativos, $\|: I$ - III - vi - IV :\|, como mostra o Ex.1. ${ }^{4}$

Primeiro, com o andamento $\cdot=100$, ouve-se esta sequência harmônica se repetir nos primeiros 2:28 do tempo de duração total de 4:26 da canção, tocada em um violão acústico com seis cordas de aço (e não de nylon), com a batida mostrada no Ex.2. A não ser pelo acorde de $\mathrm{Si}$ Maior (III grau) no segundo compasso, realizado com uma pestana a partir da segunda casa na corda Lá, todos os acordes são tocados na primeira posição. Com exceção do acorde de Dó Maior (IV grau), cuja nota Dó aguda (primeira casa na corda Si) é substituída por uma nota Ré (terceira casa na corda Si) para criar um efeito de $C^{\text {add9 }}$ (acorde de Dó Maior com nona maior acrescentada) com pedal, nenhum acorde contém notas estranhas às triades comuns (terças) em questão. ${ }^{5}$ Todos os quatro acordes na sequência de Yes we can são ritmicamente articulados de maneira semelhante (ou idêntica) àquela mostrada na batida do acorde de Sol Maior do Ex.2. A fundamental de cada acorde geralmente aparece com a duração de duas colcheias, a segunda ligeiramente abafada, seguida das notas restantes do acorde, que podem ser uma semínima ou duas colcheias com uma batida que vai do grave para o agudo, tangendo as três ou quatro cordas superiores do violão. Por exemplo, a nota mais aguda do acorde mostrado acima, um Sol, nem sempre é audível.

Não consigo pensar em nenhuma música, além de Yes we can, que corresponda exatamente a todas essas características descritas acima. Referências intertextuais apresentadas por alguns dos meus alunos e por mim mesmo, assim como aquelas dos colegas na discussão online da IASPM, todas elas mostram alguma característica estrutural comum. Mas, como veremos, alguns dados comparativos podem se mostrar mais relevantes do que outros. Em outras palavras, precisamos olhar as referências intertextuais com um foco mais preciso.
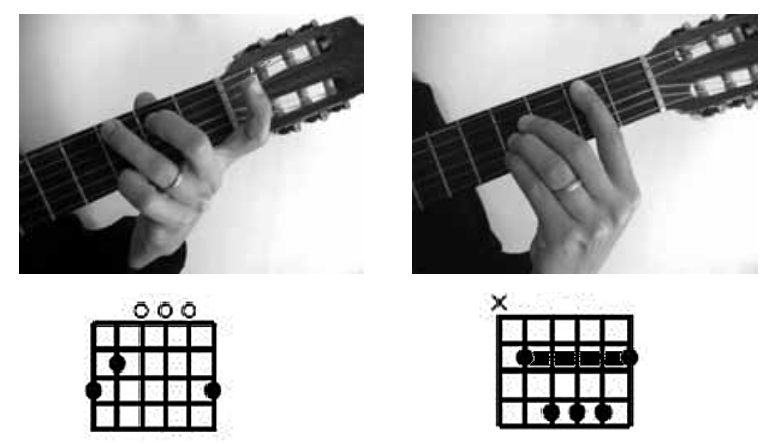
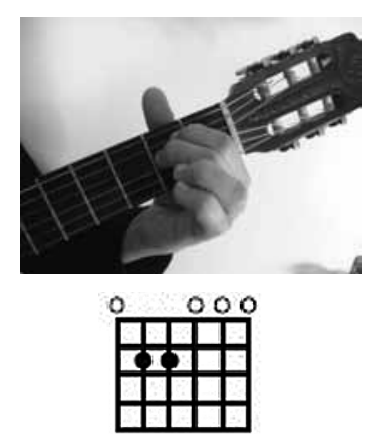
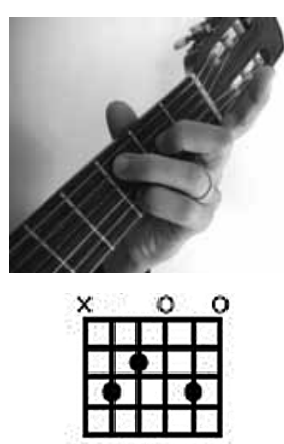

Ex.1 - Os quatro acordes do turnaround de Yes we can

(ADAMS, 2008; fotos em substituição às fotos originais publicadas no YouTube. Crédito das fotos: Dindão)

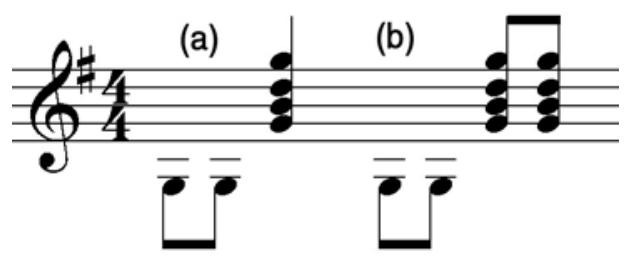

Ex.2 - A batida do violão em Yes we can 


\section{3 - A alta Renascença e a bi-modalidade andina}

As referências de Danilo Orozco às matrizes harmônicas que Carlos Vega provavelmente teria chamado de bi-modais são significativas porque há um denominador comum entre os acordes de Yes we can e, por exemplo, a gravação de Guardame las vacas a que ele se refere. ${ }^{6}$

Os acordes de Guardame las vacas mencionados por Orozco são semelhantes àqueles da canção La folia $^{7}$ cuja ubiquidade em toda a Europa na alta renascença é comparável àquela do blues de doze compassos nos Estados Unidos do século XX. Uma variação comum da matriz de La Folia se desenrola como mostrado no Ex.3:

Se o acorde finalis nessa matriz de oito compassos, um Mi Menor, for considerado como tônica principal, então as funções relativas dos outros acordes serão aquelas da linha do meio mostrada no Ex.3. Se, por outro lado, escutarmos essa matriz no tom de Sol Maior (o tom do acorde initialis), será que a linha de baixo, em itálico, seria a mais correta? Bem, de fato não, porque a matriz termina com uma inequívoca cadência perfeita $\mathrm{V}$-i (acordes de Si Maior - Mi Menor). Além disso, como ocorre na progressão de La Folia (mostrada acima), o acorde de Mi Menor é sempre precedido ou seguido apenas por tríades maiores de Ré (bVII) ou Si (V), ambas, em termos da harmonia triádica europeia, tendo a função dominante no tom de Mi Menor, especialmente o acorde do V grau (Si Maior, alterado ascendentemente para incluir a sétima Ré \#, ao invés das triades específicas Si Menor e Ré Maior do tom, que tem o Ré natural). Além disso, não há uma relação cadencial no turnaround, nem plagal nem de dominante, entre os acordes finalis e initialis seguintes. 0 mesmo acontece em muitas progressões harmônicas no estilo andino huayño, a exemplo da matriz de quatro acordes C - G - B - Em, a qual pode ser encontrada na versão de Quiaquenita (incluída em La flûte indienne, 1966) de LOS CALCHAKIS. Não consigo ouvir esta progressão como sendo totalmente no tom de Sol (IV - I - III - vi): para mim, sempre soa como bVI - blll - V - i, principalmente no tom de Mi Menor. ${ }^{8}$

Resumindo esta breve incursão pelas matrizes da alta renascença e andina, esses acordes, diferentemente daqueles de Yes we can: (1) terminam como cadências envolvendo a dominante ( $\mathrm{V}-\mathrm{i})$ no tom menor; (2) se iniciam na tríade da relativa maior ou da subdominante relati- va maior; (3) geralmente são duas vezes mais longos. Considerando outros parâmetros da expressão musical associados com os acordes de Yes we can, seria relevante também observar que; (4) os andamentos dos IOCMs andino e da alta renascença, na maioria das vezes, são mais rápidos que $\cdot=100$; (5) sua métrica geralmente não é 4/4, mas $\operatorname{sim} 3 / 4$ ou $6 / 8$, ou uma combinação de ambas formando hemíolas; (6) quando tocado com batidas do tipo rasgueado, qualquer instrumento harmônico de cordas é mais rápido do que quando dedilhado; (7) se o timbre de um violão com cordas de aço é pouco comum, o timbre de um violão com cordas de tripa ou nylon é mais comum (o som do violão "espanhol"), e o timbre mais agudo e metálico de uma bandola, tiple ou charango é ainda muito mais comum. Embora possamos especular a partir de possíveis bases comuns divergentes da imagem sônica triádica da harmonia "clássica", ligada à europeidade urbana do século XIX, as razões acima me levam a pensar que as similaridades estruturais não são suficientemente marcantes para defender uma comparação interobjetiva mais aprofundada nesta direção. Por isso, tentarei restringir as comparações, tanto quanto possivel, aos materiais que mais de perto lembram os acordes de Yes we can.

\section{4 - Quatro acordes, quatro harmonias}

Investigar o significado de uma sequência de acordes é o mesmo que tentar encontrar exemplos intertextuais de todas as harmonias presentes. Embora possa soar tautológico, vale a pena lembrar que, a não ser que a matriz comece e termine no mesmo acorde, uma sequência de três acordes contém três harmonias, uma sequência de quatro acordes contém quatro harmonias e assim por diante. Esta obviedade deve ser reafirmada porque é fácil subestimar um dos mais importantes aspectos tonais do loop de acordes: a harmonia do último acorde do turnaround e sua volta para o primeiro. Em Yes we can, isto é representado pelo movimento da cadência plagal dos acordes de Dó Maior para Sol Maior $(I V \rightarrow I)$. De fato, é esta harmonia, e não o movimento $\mathrm{V} \rightarrow$ vi (acordes de Ré Maior para Mi Menor) no meio do loop, que encerra algum potencial de finalização real. ${ }^{9}$

0 movimento plagal no sentido horário do círculo das quintas é quase tão comum em estilos como gospel, country modal, rock folk e o rock baseado no blues quanto é raro no universo das sonatas de Corelli, óperas de Wag-

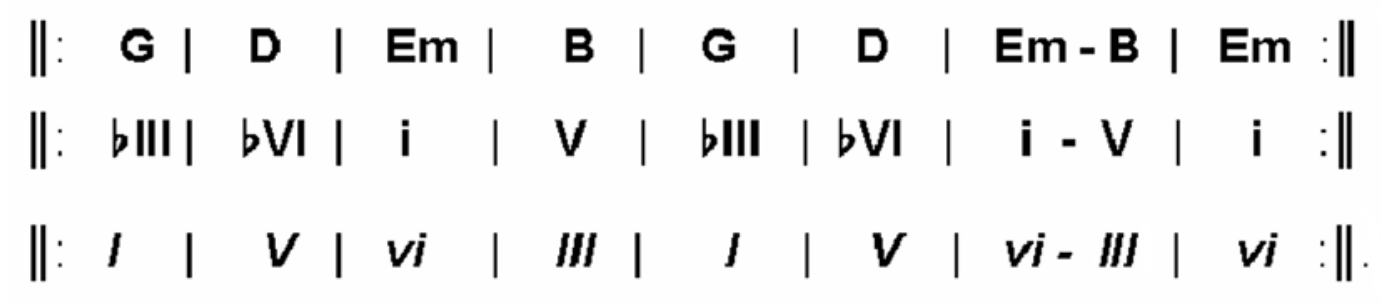

Ex.3 - Sequência harmônica da canção renascentista La Folia. 
ner, canções de câmara vitorianas, standards de jazz etc. que priorizam o sentido anti-horário do círculo das quintas. ${ }^{10}$ As harmonias do turnaround plagal de Yes we can podem, de fato, constituir uma razão pela qual nós provavelmente escutamos essa música como popular, como norte-americana e não como clássica e europeia. Podemos até escutar a referência plagal em algum Amém, canção gospel ou canção folclórica baseada na escala pentatônica maior mas, conotativamente, é difícil falar especificamente sobre o IV-I sem falar que esse encadeamento harmônico é muito idiomático nos outros estilos. E pode, mesmo, ser a marca de conclusão harmônica preferida em muitas canções no amplo leque das tradições da canção popular na língua inglesa. ${ }^{11}$ Por isso, ao invés de nos determos aí, vamos investigar o passo harmônico inicial da sequência, que é, ainda, menos comum do que o IV-I.

\section{5 - Primeiras impressões: $\rightarrow 1$}

É dito que a primeira impressão é a que fica. Este ditado certamente se aplica às partidas harmônicas porque o segundo acorde em qualquer sequência é o que cria a primeira impressão de uma progressão ou direção harmônica. Entretanto, antes de discutir o passo I-III de Yes we can, devemos considerar aquele que é o primeiro passo de fato, ou seja, o passo que leva o ouvinte da ausência musical a algo musical. Em outras palavras, partindo do antes e fora da música para o primeiro som da canção. 0 acorde de Sol Maior na primeira posição do violão acústico em Yes we can é importante porque sua sonoridade cria a primeira impressão real da canção.

Exemplos de acordes de Sol Maior na primeira posição no início de canções, com levadas rítmicas ou simplesmente dedilhados, em um violão acústico com seis cordas de metal, e com um andamento moderado ocorrem no início das seguintes gravações de Bob DYLAN: The Times they are a-changing (1964a), It ain't me babe (1964b), John Wesley Harding (1967), George Jackson (1971) e Knockin' on heaven's door (1973). ${ }^{12}$ Esse acorde de Sol Maior também ocorre como primeiro acorde da tônica com frequência em um razoável número de canções de Woody GUTHRIE como, por exemplo, Oklahoma Hills (1937), Grand Coulee Dam (1946) e Two good men (1946?). ${ }^{13} 0$ primeiro som em Yes we can é, em outras palavras, virtualmente idêntico ao primeiro som de diversas canções populares de reconhecidos cantores-compositores norte-americanos associados com políticas progressistas e mudanças sociais. Se estas alusões são intencionais ou não em Yes we can, as promessas de mudança e justiça social da recente eleição presidencial dos Estados Unidos, por outro lado, certamente poderiam estar, teoricamente, conectadas a figuras muito menos apropriadas dentro das tradições da música popular norte-americana do que Woody Guthrie e Bob Dylan. Basta imaginar as imagens, sons e palavras de artistas como Alice Cooper, Charlie Daniels ou Barry White como acompanhamento musical para uma plataforma eleitoral de um governo responsável! ${ }^{14}$ Obviamente, existe muito mais correspondência, tanto do ponto de vista da letra quanto da sonoridade, entre o "It's time for a change... " ("É hora de mudar. . .") de Obama e The Times they are a-changing ("Os tempos de mudança") de DYLAN.

Outro ponto significativo a respeito do acorde de Sol Maior, com suas quatro cordas soltas e terça dobrada (Si nas cordas Lá e Si) é que, assim como os outros dois acordes na primeira posição que se repetem (Mi Menor e Dó Maior), é fácil para qualquer violonista amador que encontramos em festinhas ou acampamentos. Os acordes de Sol Maior, Mi Menor e Dó Maior são acordes que milhões de norte-americanos podem saudar com um yes, we can!. E mesmo o acorde de Si Maior, o segundo acorde de Yes we can, que pode ser entendido como um acorde de Lá Maior tocado com uma pestana na segunda casa, não apresenta nenhum desafio técnico para o músico amador de habilidade mediana. ${ }^{15}$ Mas não é tanto a acessibilidade poïética em si mesma que é semioticamente importante, mas sim o seu significado para a maioria dos que não tocam violão, mesmo pouco. Graças ao fato de que tocar esses acordes fáceis está dentro da capacidade de uma significativa minoria da população que toca violão, a maioria da sociedade, por meio da exposição repetida a estes acordes de uma maneira simples no violão, tem aprendido a associá-los às palavras, ideias e situações que os acompanham.

\section{6 - 0 passo harmônico inicial I $\rightarrow$ III}

0 passo harmônico inicial $I \rightarrow$ III (acordes de Sol Maior para Si Maior em Yes we can) não é o início mais comum e nem o início mais incomum dos encadeamentos harmônicos da música popular na língua inglesa: $\mathrm{I} \rightarrow \mathrm{IV}, \mathrm{I} \rightarrow \mathrm{V}, \mathrm{I} \rightarrow \mathrm{Vi}$, provavelmente também $\mathrm{I} \rightarrow \mathrm{ii}$ e $\mathrm{I} \rightarrow$ iii são, provavelmente, mais comuns do que $\mathrm{I} \rightarrow \mathrm{II}$, o qual, por sua vez, talvez seja menos usual do que $\mathrm{I} \rightarrow \mathrm{I}, \mathrm{I} \rightarrow \mathfrak{l} \mathrm{III}$ or $\mathrm{I} \rightarrow b \mathrm{VII}$, mas provavelmente mais comum do que $\mathrm{I} \rightarrow \mathrm{b}$ VI (veja MOORE, 1992).

Em todo caso, o número de peças, ou seções de peças, que começam com $\mathrm{I} \rightarrow \mathrm{II}$ que chamaram minha atenção dentro do repertório relevante, ou pelo menos parcialmente relevante, não impressiona. Achei apenas onze, listadas a seguir em ordem alfabética: [1] Abilene (George HAMILTON IV, 1963); [2] Bell-bottom blues (Eric CLAPTON, 1970); [3] The Charleston (GOLDEN GATE ORCHESTRA, 1925); [4] Crazy (Patsy CLINE, 1961); [5] Creep (RADIOHEAD, 1992); [6] Jungle (ELECTRIC LIGHT ORCHESTRA, 1979); [7] Nobody knows you when you're down and out [daqui para frente chamada apenas de Down and out] (Bessie SMITH, 1929); ${ }^{16}$ [8] Dock of the bay (Otis Redding, 1968); [9] Who's sorry now (Connie FRANCIS, 1957); [10] Woman is the nigger of the world (John LENNON, 1975); [11] A World without love (PETER e GORDON, 1964). ${ }^{17}$ Inicialmente, sem saber o porquê, descobri que apenas três dessas onze canções soavam suficiente parecidas como Yes we can para serem usadas como IOCMs convincentes para a sequência de acordes em questão. Uma vez que esse tipo de "intuição" não é muito útil em si mesmo, tentarei identificar e explicar as diferenças nos parâmetros da expressão musical que se articulam aí e em conexão com o passo harmônico inicial 
I-III, comum entre Yes we can e as onze peças comparativas. Este processo de eliminação deverá melhorar o foco para se observar as características mais salientes do loop de acordes de Yes we can.

Antes de tudo, há duas características estritamente harmônicas que se destacam, do ponto de vista da semiótica, em relação à natureza do passo $\mathrm{I} \rightarrow \mathrm{III}$ : a linhas do baixo e o prolongamento harmônico. Todas as notas do baixo do loop de Yes we can coincidem com a fundamental das triades, enquanto que CLAPTON, em Bell-Bottom Blues (1970), utiliza uma linha descendente no baixo por graus conjuntos de tal forma que os acordes, de fato, progridem como I $\rightarrow \mathrm{III} \rightarrow \mathrm{vi} \rightarrow[\mathrm{I} 5 \rightarrow]$ IV (as notas do baixo, no tom de Sol Maior seriam Sol, Fá\#, Mi [Ré] e Dó; e os acordes seriam $G$, Ré/F\#, Em, G/D, C), uma progressão que contém dois acordes com inversão. Graças a precedentes famosos como Whiter shade of pale / Ária de BACH (I-V $\mathrm{V}_{3}-\mathrm{vi}^{-} \mathrm{I}_{5^{\prime}}$ etc., Bach, 1731; PROCOL HARUM, 1967), acordes invertidos com linhas do baixo por grau conjunto se tornaram um confiável símbolo pop de "eruditismo" ou "pop clássico". Trata-se de um mecanismo que retira esta canção-arranjo da esfera de participação popular, participação popular que pode ser exemplificada pelo estilo de violão toque-e-cante de Yes we can e suas tríades na posição fundamental. A utilização de acordes invertidos e graus conjuntos na linha do baixo elitizam a peça. Esta é apenas um das razões para tratar uma similaridade estrutural óbvia como a partida harmônica $\mathrm{I} \rightarrow \mathrm{III}$ com cautela. Outra razão harmônica para por em dúvida a relevância de uma comparação que envolva $\mathrm{I} \rightarrow$ III é o prolongamento harmônico. Por exemplo, somente duas das dez peças que constituem IOCMs (Dock of the bay e (reep) apresentam I $\rightarrow$ III no início do loop de quatro compassos. Muitas das outras canções, na verdade, incluem encadeamentos de harmonias com dominantes do círculo das quintas (sentido anti-horário) incompativeis com o idioma tonal geral de Yes we can. Além disso, parâmetros como andamento, padrão de acompanhamento e instrumentação podem também fazer algumas harmonias $\mathrm{I} \rightarrow \mathrm{II}$ soarem bastante diferentes daquelas de Yes we can.

As músicas The Charleston $(.=96)$ e Who's sorry now $($. = 88), por exemplo, embora sejam tocadas em um andamento semelhante ao de Yes we can $(\cdot=100)$, são muito diferentes em termos de instrumentação, rítmica e prolongamento harmônico. Tanto (1) a orquestração tradicional de jazz band em The Charleston, quanto (2) sua sonoridade lo-fi ${ }^{18}$ típica dos discos de 78 rpm, (3) quanto, no caso de Who's sorry now, sua sonoridade semi-amplificada dos pop combos da década de 1950, que se torna mais típica ainda com as tercinas constantes no piano, remanescentes do jazz "clink-clink-clink" de Stan FREBERG (1956) ${ }^{19}$, são opções comparativas muito longínquas de Yes we can, que é tocada com a simplicidade de notas e tríades de um violão acústico. 0 prolongamento do I-III em The Charleston e Who's sorry now em uma sequência de dominantes em quintas descendentes (I-III-VI-II-V-I nas tonalidades de Si b Maior e Mi b Maior, que são amigáveis para os metais e saxofones) são outras indicações óbvias dos estilos mu- sicais e conotações de um mundo distante daquele de Yes we can. As duas canções country (Abilene e Crazy) podem também ser eliminadas como IOCMs por razões semelhantes de incompatibilidade de instrumentação, padrão de acompanhamento e prolongamento harmônico. ${ }^{20}$

As canções Down and out $(. .=90,12 / 8)$, Sitting on the dock of the bay $(\cdot=103,4 / 4)$ e Creep $(\cdot=92,4 / 4)$, por outro lado, seguem no mesmo caminho de Yes we can e pertencem, todas, ao repertório pop internacional angloamericano pós-1955. Embora nenhuma destas canções apresente a batida simples de acompanhamento do cantor com violão acústico, elas se assemelham mais a Yes we can do que The Charleston, Who's sorry now, Abilene e Crazy. Apesar disto, existem diversas diferenças estruturais importantes entre as três canções em discussão (Down and out, Dock of the bay e Creep) e, por outro lado, Yes we can. Por exemplo, todas as gravações de Down and out, sejam elas com..$=90$, tanto na gravação de Bessie SMITH (1929) quanto na de Eric CLAPTON (1992), sejam muito mais lentas, com o próprio CLAPTON (1970) ou Stevie WINWOOD (1966), todas elas tem o acompanhamento shuffle do blues lento ( $[T$, mesmo quando notado como ..), tendo como acompanhamento a corneta, o piano e a tuba (na gravação de Bessie Smith) ou a guitarra elétrica, o órgão Hammond e a bateria (nas gravações de Clapton e Winwood), enquanto que os acordes Yes we can são apresentados em colcheias sem swing ... A ${ }^{21}$ Além disso, o passo I-III inicial de Down and out segue com uma progressão de quintas descendentes que inclui o VI grau ( $\mathrm{E}$ ou E7), ao invés do vi grau (Em), depois inclui o ii grau (Am) e, depois, passa por harmonias como \#IVdim (C\#dim), para seguir com II7 (A7), V7 (D7) e I (G). Não se ouve nenhum acorde diminuto ou uma extensa progressão com dominantes no círculo da quintas em qualquer parte de Yes we can. Esta canção foi concebida em um idioma diferente, seja nos aspectos tímbrico, métrico, rítmico ou tonal.

Sitting on the dock of the bay (REDDING, 1968), por outro lado, é em colcheias contínuas e sem swing ... e apresenta os quatro acordes de sua sequência virtualmente no mesmo andamento $(.=104)$ de Yes we can: I - III - IV - II (G - B - C - A). Esta sequência de Dock of the bay é notável porque não contém nenhum passo harmônico plagal $(\mathrm{IV} \rightarrow \mid)$ ou de dominante $(\mathrm{V} \rightarrow \mid \mathrm{)}$. Somente uma ponte de 19 segundos (1:24 - 1:43) do total dos 2:45 da canção inclui uma breve progressão: bVII $\rightarrow \mathrm{V} \rightarrow \mid$ (1:37 1:43) que leva de volta à sequência de acordes harmonicamente estática que ocupa toda a gravação, exceto por alguns segundos. A sequência de Dock of the bay é interessante também porque consiste em dois pares de acordes: primeiro, o I e o IV graus (Sol Maior e Dó Maior no tom de Sol Maior), que estão próximos entre si no círculo das quintas; segundo, o III e o II graus (Si Maior e Lá Maior no tom de Sol Maior), ambos para o lado dos sustenidos no círculo das quintas (longe dos graus I e IV) e separados entre si apenas pelo VI grau (Mi Maior). Mas esses quatro acordes não são tocados nessa disposição - experimente o efeito de tocá-los, ao contrário, na sequ- 
ência G-C-A-B ou, então, G-B-A-C[-G] -, uma vez que I e III $(\mathrm{G} \rightarrow \mathrm{B})$ pertencem à mesma frase que Redding canta "Sitting on the dock of the bay. .." ("Sentado na doca da baía..."), depois da qual ele respira. Após esta cesura no meio da canção, ele canta "Watching the tide roll in... " ("Olhando a maré que chega. ..") na segunda metade do loop de acordes (no seu encadeamento $I V \rightarrow I I, C \rightarrow A$ ), que é um tipo de I-VI em Dó Maior, refletindo o mesmo tipo de distância harmônica de terça, como no encadeamento I-III (na primeira metade do loop, $\mathrm{G} \rightarrow \mathrm{B}$ ).

Não haveria nada de especial a respeito desta divisão da sequência em duas partes se os dois acordes triádicos, em cada metade, estivessem mais perto um do outro no círculo das tonalidades. Mas não é o caso. A segunda tríade de cada par, Si Maior e Lá Maior, situa-se distante não apenas um ou dois passos harmônicos de quinta da primeira tríade, mas a uma distância de quatro passos harmônicos no círculo das quintas (Sol Maior $\rightarrow$ (Ré Maior $\rightarrow$ Lá Maior $\rightarrow$ Mi Maior $) \rightarrow$ Si Maior ou, em termos relativos, $\mathrm{I} \rightarrow(\mathrm{V} \rightarrow \mathrm{II} \rightarrow \mathrm{VI}) \rightarrow \mathrm{II})$ e a uma distância de três passos harmônicos no círculo das quintas (Dó Maior $\rightarrow$ (Sol Maior $\rightarrow$ Ré Maior) $\rightarrow$ Lá Maior ou, em termos relativos, IV $\rightarrow(I \rightarrow \mathrm{V}) \rightarrow \mathrm{I})$, respectivamente. É isto que faz a sequência de Dock of the baysoar como dois acordes vai-e-vem (shuttle chords) semelhantes, um após o outro - um constante movimento para frente e para trás - ao invés de uma sequência única e repetida de acordes como I-vi-IV-V ou I-V-bVII-IV. Este movimento de vai-evem em Dock of the bay, que é sublinhado pelo acréscimo de efeitos sonoros de praia como ondas que vem e vão, estão ausentes, é claro, em Yes we can, cuja sequência de acordes contém dois passos harmônicos de tonalidades vizinhas muito claros: Si Maior $\rightarrow \mathrm{Mi}$ Menor $(\mathrm{III} \rightarrow \mathrm{vi}$, com função dominante) e Dó Maior $\rightarrow$ Sol Maior (IV $\rightarrow$ I, com função plagal), o que dá a ela um definitivo caráter de repetição e não de vai-e-vem duplo. ${ }^{22}$

Nada disso significa que Sitting on the dock of the bay é inadmissivel como uma evidência IOCM dos acordes de Yes we can. Mesmo que o caráter de vai-e-vem harmônico da gravação de Redding, seu prolongamento harmônico e sua orquestração divirjam claramente de Yes we can, sua ponte repete uma curta frase melódica (no trecho "Nothing's gonna change..." ["Nada irá mudar. .."], "I can't do what ten people tell me to do..." ["Não posso fazer o que dez pessoas me pedem para fazer. . "], etc., 1:24-1:37) que recorre de maneira semelhante em 0:31 de Yes we can ("It was sung by immigrants..." ["Era cantado pelos imigrantes. .."]). ${ }^{23}$ Como apontou bem Barbara Bradby na seu e-mail na lista da IASPM, aquela frase de Yes we can chega muito perto da declamação inicial "When the night..." ["Quando a noite. .. "] em Stand by me (1961) na voz de Ben E. KING. Eu acrescentaria que as frases melódicas em cada uma dessas três canções podem ser caracterizadas como proclamatórias, sinceras e apaixonadas. Eu também caracterizaria essas frases como sendo frases tipicamente masculinas dos cantores soul da década de 1960 (por exemplo, Otis Redding, Wilson Picket, Marvin Gaye), que estão associados à luta norte-americana pelos Direi- tos Civis e com o tipo de engajamento social que Michael Haralambos documenta em Right on! From blues to soul in black America (HARALAMBOS, 1974). Se há alguma validade nesta análise da frase no ponto 0:31 de Yes we can, a conexão com o I-III de Dock of the bay se reforça ciclicamente por associação-cruzada. Sua corrente de conotações contém os seguintes tipos de elos indexadores: (1) a frase melódica de Yes we can lembra arquétipos melódicos cantados por cantores homens de música soul na final da década de 1960; (2) a música daquela época estava associada a uma imagem mais esperançosa e assertiva entre os afro-americanos nos Estados Unidos, (3) um dos mais famosos desses cantores foi Otis Redding, sendo Sitting on the dock of the bay um de seus maiores sucessos; (4) essa canção também contém o mesmo passo harmônico I-III como ocorre em Yes we can, a canção da campanha presidencial de Barak Obama; (5) o governo presidencial de Obama marca outra grande mudança positiva nos Direitos Civis dos Estados Unidos.

A canção Jungle (1979) da banda ELO, mencionada por Allan Moore, é no mesmo andamento de Yes we can $(.=100)$. Seus três primeiros encadeamentos harmônicos são idênticos àqueles da canção de Obama: Ré Maior - Fá \# Maior - Si Menor - Sol Maior (Jungle, no tom de Ré Maior) = I III vi IV = Sol Maior - Si Maior - Mi Menor - Dó Maior (Yes we can, no tom de Sol Maior). "Na mosca!", poderíamos pensar. De fato, parece haver aí 100\% de correspondência. Mas há um problema, uma vez que esta correspondência perfeita não soa exatamente como os acordes de Yes we can. Existem pelo menos quatro razões para não se encaixarem: (1) os acordes da banda ELO não são utilizados em loop; (2) a sequência da banda ELO segue com uma cadência $V \rightarrow I(A \rightarrow D)$ repetida, (3) os quatro acordes cobrem dois compassos, e não quatro, e são espaçados assim: I d. . I l. . I, com apenas uma nota para cada acorde, e não um compasso inteiro de..... , ou $. \downarrow . .$. , ou qualquer outra padrão similar para cada acorde; (4) a instrumentação é totalmente diferente, preenchida com instrumentos tropicais do tipo "world music" associados, pelo menos na cultura musical urbana e nãotropical do "primeiro-mundo", como o título da canção: Jungle (Selva). Posso escutar instrumentos que lembram o agogô, o guiro [tipo de reco-reco da América Central], cowbell, wood block e maracas. Mais ainda - e já fora da conotação deste campo (ou selva, para ser mais preciso), um bem audivel e denso string pad [um sample sintetizado do naipe das cordas orquestrais]. Todas estas diferenças me deixam relutante para fazer referência aos acordes da banda ELO como um IOCM para os acordes de Yes we can de Obama, apesar da correta similaridade em termos de uma teoria harmônica convencional. Estas duas canções simplesmente não soam suficientemente similares.

Um raciocínio semelhante pode ser aplicado à canção Woman is the nigger of the world (1975) de John LENNON, embora por diversas razões de dessemelhança. Além do fato de que a sequência de John Lennon não é um loop, mas parte de uma sequência de um chorus de oito compas- 
sos (|| I - III - vi - I - IV - iv- I - I || no tom de Mi Maior), a batida da canção de Lennon é suingada (12/8 feel), o efeito geral da intensidade sonora muito mais alto, o registro vocal mais agudo e o timbre mais rascante do que em Yes we can. Há também diferenças radicais de instrumentação entre as duas canções, sendo que a música de Lennon inclui um piano percussivo, guitarra e contrabaixo elétricos, um saxofone estridente em primeiro plano e eventos de alta intensidade na bateria. Não se ouve nenhuma dessas características na canção de Obama.

Restam apenas duas músicas de IOCM $\rightarrow$ III para discutir, a canção $A$ World without love (PETER e GORDON, 1964) de Lennon e McCartney e Creep da banda de rock inglesa Radiohead (RADIOHEAD, 1992).

De 1964 até recentemente, trabalhei equivocadamente achando que os primeiros quatro compassos de cada verso de $A$ World without love eram harmonizados com os acordes Mi Maior | Sol \# Maior |Dó \# Menor | Lá Maior (I-III-vi-IV), ou seja, a mesma progressão relativa do loop de acordes de Yes we can. A sequência, de fato, é Mi Maior | Sol \# Maior | Dó \# Menor | Dó \# Menor (I-IIIvi-vi). E a toquei com harmonia errada muitas vezes sem que qualquer ouvinte ou colega músico tenha reclamado, provavelmente porque a única nota melódica no quarto compasso, um Dó \#, soa bem tanto sobre um acorde de Lá Maior quanto de Dó \# Menor. 0 meu ponto de vista, neste caso, é sugerir mais uma vez que a correspondência harmônica exata não é necessariamente o fator mais importante, se uma sequência de acordes em uma música soa como uma sequência de acordes de outra música. Neste contexto, isto significa que a parecença harmônica mais importante entre $A$ World without love e Yes we can é o fato de ambas compartilharem os mesmos passos harmônicos iniciais $\mathrm{I} \rightarrow \mathrm{III} \rightarrow$ vi. Mas a sequência de Lennon e McCartney soa diferente de Yes we can principalmente porque: (1) a primeira é cantada em um andamento mais rápido $(.=134)$; (2) o acompanhamento é dominado pelas pela pesada figuração .. . . . . "one-five oompah" do baixo de Paul McCartney; ${ }^{24}$ (3) o seu I-III-vi não se repete em loop. Dito isto, o I-III-vi-vi em World Without Love não ocorre regularmente no início de cada verso em compasso 4/4 sem swing, com um acorde por compasso e com a batida do acompanhamento básico do violão acústico, mesmo que pouco audivel na mixagem. Além disso, o prolongamento harmônico I - iv - I - I - ii - V - I (acordes de Mi Maior - Lá Menor - Mi Maior - Mi Maior - Fá \# Menor - Si Maior - Mi Maior) em World without Love permanece dentro do mesmo idioma de tríades comuns no estado fundamental como em Yes we can, enquanto que sua instrumentação pop simples tem muito mais em comum com Yes we can do que Jungle da banda ELO, Woman is the nigger of the world de Lennon, isto para não citar The Charleston (que recebeu muitas gravações, inclusive da Golden Gate Orchestra) e Down and out com Bessie Smith etc. ${ }^{25}$ Como em Dock of the bay, o I III em World without love não compartilha com Yes we can alguns elementos estruturais comuns.
Entretanto, diferentemente de Dock of the bay, a gravação de Peter \& Gordon não contém nenhum elemento de soul or gospel que dirija o ouvinte em direção a qualquer tipo de conotação relativa aos Direitos Civis. Se isto é verdade, que tipo de mensagem paramusical World without love contem? Vejamos seus versos [com o texto original após a tradução]:

[verso 1, verso 3] Por favor, prenda-me longe daqui e não permita o dia aqui dentro, onde me escondo com minha solidão. Não me importo com que dizem, não vou viver em um mundo sem amor.

[verso 2] Pássaros cantam desafinados e nuvens de chuva escondem a lua. Estou bem, aqui ficarei com minha solidão. Não me importo com que dizem, não vou viver em um mundo sem amor.

[ponte] Aqui vou esperar, daqui a pouco verei o sorriso do meu amor. Ela virá, não sei quando. Quando vier, perco, por isso baby, até lá.

[v. 1, v.3] Please lock me away and don't allow the day here inside where I hide with my loneliness. I don't care what they say I won't stay in a world without love.

[v.2] Birds sing out of tune and rain clouds hide the moon. I'm OK, here I'll stay with my loneliness. I don't care what they say I won't stay in a world without love.

[bridge] Here I wait and in a while I will see my lover smile. She may come, I know not when. When she does I lose, so baby until then.

À primeira vista, as divagações deste jovem e apaixonado rapaz não têm nada a ver com a luta, esperança e coisas cotidianas que podemos encontrar nas frases de efeito dos discursos de Obama que ocorrem ao longo de Yes we can. Assim, basta escarafunchar um pouco abaixo da superfície da letra de Lennon e McCartney para encontrar um paralelo: um processo emocional que, se pudermos simplificar, vai do relativo desespero e escuridão a uma relativa esperança e luz, sempre com o mesmo sentido de determinação.

A sequência harmônica na canção Creep de Radiohead é o loop $\|:|\rightarrow||| I \mid \mathrm{V} \rightarrow$ iv : || (Sol Maior | Si Maior | Dó Maior | Dó Menor) com $\cdot=92$ durante os quatro minutos que dura a canção. Cada loop cobre quatro compassos, com um acorde por compasso e rítmica de quatro colcheias ou semínimas sem swing na bateria e no violão ( ... no ximbau) e o padrão de simples .. I I . . . no baixo. Considerando o movimento de acompanhamento como um todo, estas partes são mais semelhantes ainda ao padrão. . do violão acústico de Yes we can do que aqueles de Dock of the bay. $\mathrm{E}_{\text {, }}$ certamente, são muito mais próximos da canção de Obama do que o padrão | $\mid$. . | da banda ELO, ou o padrão suingado 1. ... $) \mid$ de Down and out ou de Woman is the nigger of the world, ou o padrão $|. . . . .0|$ de Who's sorry now. E, como acabei de afirmar, eles são, da mesma forma que Yes we can, repetidos sobre o mesmo período de quatro compassos em 4/4. Além disso, as harmonias do turnaround do loop de Radiohead, que vão de Dó Menor para Sol Maior (iv $\rightarrow$ I) é plagal como o turnaround de Yes we can, e os padrões de acompanhamento são todos epítomes de um estilo pop-rock sem firulas (desenhos de ximbau standard simples na bateria, arpejos simples no violão, virtualmente sem reverberação ou qualquer outro tratamento de sinal sonoro etc.). A estética da essência crua em Creep se alinha bem com o caráter sem firulas do som do violão em Yes we can. 
Nenhuma das similaridades acima mencionadas pode refutar o fato de que há claras diferenças entre Creep e Yes we can, sendo a mais óbvia a gritaria nervosa e alienada e a guitarra elétrica com um poderoso overdrive ocorrendo em 39\% do tempo da faixa rock de Radiohead. ${ }^{26}$ Harmonicamente, há outra diferença importante: enquanto que Yes we can repete a sequência I-III-vi-IV, o loop em Creep segue o encadeamento IIII-IV-iv. Isto significa que, embora o turnaround em ambas as canções sejam plagais, o acorde de IV grau (Maior) em Creep ocorre um compasso antes, no lugar do Mi Menor (vi) de Yes we can e a tríade de Dó Maior (IV grau) de Yes we can ocorre na mesmo posição do loop do Dó Menor (iv grau) de Radiohead. Este acorde de Dó Menor, com sua nota Mib, enarmonicamente contrastando, em termos de direcionalidade de condução de voz, contra a nota Ré \# ascendente do acorde de Si Maior, imprime ao loop de Creep um caráter único que pode contribuir para o dramático sentido de desesperança da canção: ${ }^{27}$ o Ré \# sobe para o Mi natural, mas o Mib repetidamente reverte este movimento para baixo fechando novamente sobre o Ré natural e Sol. Yes we can não contém nenhum cromatismo descendente.

Apesar das claras diferenças entre Yes we can e Creep, essas duas canções definitivamente compartilham mais coisas em comum do que o encadeamento inicial I-III do loop quaternário de quatro compassos em Sol Maior. A questão é: como uma canção raivosa de auto-comiseração, que trata de um personagem pilantra e esdrúxulo pode ter alguma coisa musicalmente significativa em comum com um personagem que afirma uma crença coletiva na esperança, como ocorre em Yes we can. Uma razão poderia estar na ideia levantada por outros membros da IASPM, a de que o encadeamento apresenta uma forte qualidade de movimento para um lugar diferente, do tipo para cima e para fora que se observa no baixo ascendente I-III-vi e no movimento melódico 5 - \#5 - 6 (voz interna Ré - Ré\# - Mi) já mencionado; e que este movimento para cima e para fora indo para um lugar diferente é essencial tanto para expressar confiança na superação de dificuldades - "yes, we can" ("sim, nós podemos"'), quanto para vociferar aversão a qualquer coisa que gere auto-repulsa. 0 loop de acorde de Yes we can não tem a escorregada cromática descendente de Creep, nem seu encadeamento I-III, seguido pelo segundo encadeamento IV-II (Dó Maior - Lá Maior) direcionalmente "de engano" de Dock of the bay, possui nenhum dos efeitos para frente-e-para trás daqueles dois acordes vai-e-vem daquela canção. De fato, para aprofundarmos na questão do significado dos acordes de Yes we can, precisamos examinar o material comparativo que apresenta os outros dois acordes do loop da canção de Obama: vi e IV. Para ser mais preciso, precisamos encontrar 10CMs que apresentem loops harmônicos no esquema I - $x$ - vi - IV, no qual $x$ é um alternativa para III como meio viável de passar de I para vi. 0 acorde $x$ mais comum seria, é claro, iii ou V (no tom de Sol Maior: Si menor ou Ré Maior).

\section{7 - I - iii - vi - IV}

Os quatro primeiros acordes de What becomes of the brokenhearted? (RUFFIN, 1966) são Bb $\rightarrow \mathrm{Dm} \rightarrow \mathrm{Gm} \rightarrow$ Eb (ou, em termos relativos, $\mathrm{I} \rightarrow \mathrm{iii} \rightarrow \mathrm{Vi} \rightarrow \mathrm{IV}$ ), que parece ser o que estamos procurando. Infelizmente, este não é o $10 C M$ curinga que precisamos, porque a sequência de acordes na verdade se apresenta com inversões, $\mathrm{Bb} / \mathrm{F} \rightarrow \mathrm{Dm} / \mathrm{F} \rightarrow \mathrm{Gm} \rightarrow \mathrm{Eb} / \mathrm{G}$ (ou, em termos relativos, $\mathrm{I}_{5} \rightarrow \mathrm{iii}_{3} \rightarrow \mathrm{vi} \rightarrow \mathrm{IV}_{3}$ ): três das quatro tríades estão invertidas. É verdade que não há uma linha do baixo em graus conjuntos cobrindo o intervalo de uma quarta justa ou intervalo maior nesta sequência, como ocorre em $A$ Whiter shade of pale (PROCOL HARUM, 1967) ou, na voz de Clapton, Bell-Bottom blues (DEREK AND THE DOMINOES, 1970). Entretanto, as inversões das triades e o caráter de nota pedal na linha do baixo na canção de Ruffin criam um efeito parcial de estaticidade harmônica que não se resolve em um movimento substancial até muito mais à frente na peça. Além disso, assim como Bell-bottom blues de Clapton, a sequência inicial de What becomes of the brokenhearted? não é em loop e seu prolongamento contém harmonias incompativeis com os acordes no estado fundamental e sistematicamente sem swing de Yes we can. ${ }^{28}$ Soma-se a isso o fato de que a canção da Mowtown é claramente orquestrada de maneira muito diferente, com piano, cordas, backing vocals e percussão. Talvez o @... em 4/4 e com $\downarrow=100$ com timbre de voz masculina, semelhante ao que se ouve em 0:31 na canção de Obama possa atenuar algumas das diferenças acima mencionadas. Se for o caso, conexões interobjetivas eventuais entre elas são improváveis de fundamentarem uma parecença harmônica audivel.

Incipts harmônicos I-iii no estado fundamental não são incomuns em outros tipos de canção da música pop anglofônica. Por exemplo, Puff the magic dragon (PETER, PAUL \& MARY, 1963), The Weight (THE BAND, 1968) e Daniel and the sacred harp (THE BAND, 1970), todas começam com I-iii-IV, enquanto que Sukyaki (SAKAMOTO, 1963) ${ }^{29}$ e Hasta mañana da banda sueca Abba (ABBA, 1974), ambas apresentam a progressão Iiii-vi. 0 encadeamento harmônico ocorrendo mais no meio da canção e progredindo do I grau para o IV ou vi graus, passando antes pelo iii grau, também ocorre em Hangman (Peter, Paul and Mary, 1965), assim como em pontos proeminentes de It's all over now Baby Blue (1965: I-iii-IV) e I pity the poor immigrant (1968: I-iiivi) de Bob DYLAN. ${ }^{30}$ Exceto por Sukiyaki e Hasta Maña$n a$, todas essas canções pertencem aos repertórios folk e folk rock norte-americano. Além disso, a canção Hangman, as duas canções de Dylan e as duas faixas da banda de rock canadense The Band (que acompanhou Dylan entre 1964 e1967) apresentam letras que divergem da temática de amor, diversão, raiva adolescente e nostalgia do pop. Apenas uma das canções, The Weight, utiliza um loop de acordes, I-iii-IV-I com . $=124$ em um 4/4 regular com um acorde por compasso. Assim como Hangman, a letra de The Weight conta uma história de experiências negativas e positivas, 
contrastantes, enquanto que o l-iii-vi de I pity the poor immigrant de Dylan acompanha a virada em direção à justiça no final de cada verso. ${ }^{6}$ Por outro lado, embora todas essas canções apresentem um violão com batidas simples em progressões I-iii-IV ou I-iii-vi, com todos os acordes no estado fundamental, apenas uma delas (The Weight) apresenta um loop de acordes, e mesmo assim, como uma unidade de três acordes, e não de quatro. Mais ainda, nenhuma das canções tem a progressão I-iii-vi-IV, que seria a variante mais próxima do I-III-vi-IV de Yes we can. Resumindo, mesmo que haja similaridades e algumas possíveis referências às canções folk e folk rock norte-americanas com letras sérias, realmente precisamos buscar similaridades harmônicas mais convincentes em outras plagas.

\section{8 - I - V - vi - IV}

A segunda de nossas duas alternativas para o III grau como elemento de ligação entre o I e o vi graus (entre Sol Maior e Mi Menor em Yes we can) é o V grau (Ré Maior em Sol Maior). A simples questão harmônica que se coloca é que o $\mathrm{V}$ grau é o relativo maior do iii grau (uma tríade de tonalidade específica em estado fundamental no terceiro grau da escala maior) e que, assim como o ii grau ou o III grau, o V grau contém duas notas adjacentes à tríade alvo, que é o vi grau. ${ }^{32}$ Esta alternativa do segundo acorde muda o loop de I-III-vi-IV (Yes we can) para I-V-vi-IV. Convenhamos que esta sequência soa bastante similar ao início do Canon de Pachelbel - ||: V | vi -iii | IV-I | IV-V $: \|$-, um padrão que parece ter sido disseminado amplamente na música pop de língua inglesa. ${ }^{33}$ Esta progressão de acordes constitui toda a base harmônica de All together now (1991) da banda de Liverpool THE FARM, com andamento $\cdot=108 \mathrm{em}$ 4/4 e sua taxa de ritmo harmônico de um acorde por compasso. ${ }^{34}$ Mais especificamente, a sequência I-V-vi-IV, também em 4/4 e com taxa de um acorde por compasso, pode ser escutada no início de cada verso de Let it be (1970: $\bullet=76|\mathrm{C}| \mathrm{G}|\mathrm{Am}| \mathrm{F})$ dos BEATLES, bem como, com taxa de dois acordes por compasso, em No woman no cry (1974: $d=78$ |C G3|Am F) de Bob MARLEY. 0 mesmo I-V-vi-IV também acompanha a deixa do coro em Country roads (1971: $\_=80|\mathrm{D}| \mathrm{A} \mid \mathrm{Bm}$ G) de John DENVER e Not ready to make nice (2006: -=86 ||: G |D |Em |C:\| ) da banda country norte-americana DIXIE CHICKS. ${ }^{35}$ Esta sequência de acordes também ocorre em canções barulhentas e otimistas de rock como We're not going to take it (TWISTED SISTER, 1984: - $=144$ ) ou Another girl another planet (THE ONLY ONES, 1978: =156), mas o andamento, ritmica, instrumentação e tipo de impostação vocal nessas canções seriam uma tentativa muito distante do caminhar relativamente tranquilo e ordenado, sem firulas dos acordes de Yes we can. ${ }^{36}$ De fato, a sequência de acordes da canção de Obama utiliza um andamento e um ritmo de discurso que têm muito mais em comum com as canções extremamente populares mencionadas antes. Mas a história não acaba ai. All together now, Let it be, No woman no cry, Country roadse Not ready to make nice, todas elas têm um caráter antêmico. Todas elas são eminentemente cantaroláveis e todas elas apresentam letras que expressam esperança ou estímulo frente a problemas ou tempos difíceis. Tudo bem, a letra de Country roads menciona, apenas de passagem, um discreto arrependimento - "Tenho a sensação de que deveria ter voltado pra casa ontem. .." - mas todas as outras apresentam, claramente, experiências tanto de dificuldades quanto de esperança, como mostra o Ex.4.

0 vídeo Yes we can com a canção Yes we can encapsula os tipos de sentimentos listados na coluna Esperança, estímulo, determinação da tabela acima (Ex.4). A coluna Problemas, no caso da canção de Obama, seria preenchida com citações como "escravos e abolicionistas", "imigrantes [que desbravam] os confins implacáveis", "os trabalhadores [que tiveram de] organizar", "as muIheres [que tiveram] de lutar pelo voto", "os obstáculos [que] estão no nosso caminho", o "coro de cínicos que fala mais alto e mais dissonante", e "a garotinha que estuda na escola desmoronando em Dillon". Além do slogan "Yes we can" que diz tudo, a coluna três também abrigaria "eles forjaram um trilha", "Rei que nos levou ao topo da montanha e nos apontou o caminho da Terra Prometida", "oportunidade e prosperidade", "curar esta nação", "consertar este mundo", "nunca houve nada de falso com a esperança" etc.

Embora nenhuma das quatro canções mencionadas no Ex.4 apresente um acompanhamento de violão de seis cordas com batida simples, todas elas, assim como Yes we can, transcorrem com a regularidade de um acorde para cada compasso ao longo de períodos de 4 compassos em métrica 4/4. Dois deles (No woman no crye Not ready to make nice) repetem a sequência I-V-vi-IV pelo menos duas vezes em seguida, enquanto que a letra de todas as canções, incluindo Yes we can, justapõe experiências de dificuldades e esperança.

\section{8 - IOCM em combinação}

Seria realmente uma surpresa se houvesse qualquer outra canção que contivesse o mesmo tipo de loop de acordes, como ocorre em Yes we can, tocada com andamento semelhante e de maneira semelhante em relação à instrumentação, tonalidade e métrica. Por outro lado, - IOCM apresentado acima mostra que uma variedade de elementos encontráveis na tradição da música pop de língua inglesa está incorporada na sequência de acordes de Yes we can. Deve-se deixar claro também que aqueles elementos estruturais específicos são geralmente associados àquelas tradições com noções, atitudes, emoções, atividades, eventos e processos que, juntos, constroem um campo semântico razoavelmente coerente e conotativo. As características estruturais mais importantes e seus principais PMFCs (Campos Paramusicais Conotativos, do inglês Paramusical Fields of Connotation) podem ser sumariados, a grosso modo, na tabela do Ex.5.

Resumindo, há boas razões para acreditar que os acordes de Yes we can, ao recorrerem a tradições específicas da música popular em língua inglesa, contribuem para co- 


\begin{tabular}{|c|c|c|}
\hline Canção & Problemas & Esperança, estímulo, determinação \\
\hline $\begin{array}{c}\text { The Farm: } \\
\text { All together now } \\
\text { (1991) }\end{array}$ & $\begin{array}{l}\text { "...forefathers died, lost in } \\
\text { millions for a country's pride"; } \\
\text { "All those tears shed in vain; Noth- } \\
\text { ing learnt and nothing gained". } \\
\text { ["... antepassados morreram, perdidos entre } \\
\text { milhões pelo orgulho de um país"; "Todas } \\
\text { aquelas lágrimas derramadas em vão; não } \\
\text { aprendemos nada e não ganhamos nada".] }\end{array}$ & $\begin{array}{l}\text { "...they stopped fighting and they were one"; } \\
\text { "'hope remains"; "'Stop the slaughter, let's go } \\
\text { home"; ... "joined together"; "All together now". } \\
\text { ["... eles pararam de lutar e se tornaram um } \\
\text { só"; "a esperança permanece"; "Pare a ma- } \\
\text { tança, vamos para casa"; "...unidos"; "Todos } \\
\text { juntos agora".] }\end{array}$ \\
\hline $\begin{array}{l}\text { Beatles: } \\
\text { Let it be (1970) }\end{array}$ & $\begin{array}{l}\text { "times of trouble"; "the broken heart- } \\
\text { ed people"; "the night is cloudy" } \\
\text { ["tempos dificeis"; "o povo desiludido"; "a } \\
\text { noite está nublada".] }\end{array}$ & $\begin{array}{l}\text { "Mother Mary comes to me"; "words of wisdom"; } \\
\text { "There will be an answer"; "Still a chance"; "A } \\
\text { light that shines on me". } \\
\text { ["Mãe Maria venha a mim"; "palavras sábias"; } \\
\text { "Haverá uma resposta"; "Ainda uma chance"; } \\
\text { "Uma luz que brilha em mim".] }\end{array}$ \\
\hline $\begin{array}{c}\text { Bob Marley: } \\
\text { No woman no cry } \\
(1974 / 5)\end{array}$ & $\begin{array}{l}\text { "The government yard in Trenchtown"; "ob- } \\
\text { serving the hypocrites"; "good friends we've } \\
\text { lost".. } \\
\text { ["0 quintal do governo em Trenchtown"; } \\
\text { "observando os hipócritas"; "os bons amigos } \\
\text { que perdemos".] }\end{array}$ & $\begin{array}{l}\text { "No woman no cry"; "dry your tears"; "I'll share } \\
\text { with you"; "got to push on through". } \\
\text { ["Não, mulher, não chore"; "seque suas } \\
\text { lágrimas"; "Dividirei com você"; "temos que } \\
\text { continuar".] }\end{array}$ \\
\hline $\begin{array}{l}\text { The Dixie Chicks: } \\
\text { Not ready to make } \\
\text { nice (2006) }\end{array}$ & $\begin{array}{l}\text { "I've paid a price and I'll keep paying"; "too } \\
\text { late to make it right"; "sad, sad story"; "my } \\
\text { life will be over". } \\
\text { ["Paguei um preço e continuarei pagando"; } \\
\text { "tarde demais para consertar"; "triste, triste } \\
\text { história"; "minha vida será finda".] }\end{array}$ & $\begin{array}{l}\text { "I'm through with doubt"; "I'm not ready to back } \\
\text { down"; [I won't] "do what... you think I should". } \\
\text { ["Chega de dúvidas"; "Não estou disposto me } \\
\text { retirar"; "Não farei ... o que você acha que eu } \\
\text { deveria".] }\end{array}$ \\
\hline
\end{tabular}

Ex.4 - Tabela comparativa com frases-chave "superando dificuldades" em letras de canções pop antêmicas que apresentam a variante I-V-vi-IV dos acordes de Yes we can

\begin{tabular}{|c|c|c|}
\hline $\begin{array}{l}\text { Características estruturais gerais } \\
\text { (sempre } 4 / 4 \mathrm{em} \\
\text { andamento moderado) }\end{array}$ & $\begin{array}{c}\text { Gênero(s) } \\
\text { (anglófono[s]) }\end{array}$ & $\begin{array}{c}\text { Conotações } \\
\text { (PMFCs) }\end{array}$ \\
\hline $\begin{array}{l}\text { Sol Maior e outros acordes fáceis em } \\
\text { violão acústico com } 6 \text { cordas de metal }\end{array}$ & $\begin{array}{l}\text { Relacionado } \\
\text { ao folk }\end{array}$ & $\begin{array}{l}\text { Fácil de tocar, participativo, democrático, politicamente } \\
\text { progressista, "sim, nós podemos" }\end{array}$ \\
\hline I - III & Pop & $\begin{array}{l}\text { Orientação para cima e para fora, possivelmente } \\
\text { problemático }\end{array}$ \\
\hline I - iii - vi & $\begin{array}{l}\text { Folk, folk rock, } \\
\text { country rock }\end{array}$ & Narrativo, do povo \\
\hline IV - I & Gospel, soul, rock & $\begin{array}{l}\text { Pop de lingual inglesa, afirmativo, determinado, partici- } \\
\text { pativo ("Amém") }\end{array}$ \\
\hline$I-V-v i-I V$ & Pop, rock & $\begin{array}{l}\text { Vai da dificuldade ao estímulo, determinação e esperança, } \\
\text { antêmico, participativo, politicamente progressista }\end{array}$ \\
\hline
\end{tabular}

Ex.5 - Tabela-resumo dos IOCMs harmônicos e seus respectivos PMFCs em Yes we can. 
notações de estímulo, engajamento, afirmação, divisão do poder e participação democrática que parece fazer parte do ethos e programa político de Barack Obama. A justaposição entre dificuldade e esperança que se observa no IOCM I-V-vi-IV (Ex.4) corresponde às citações do discurso de Obama sobre escravos, abolicionistas, imigrantes, trabalhadores, mulheres e sua determinação em superar as diversas formas de injustiça. Olhando de perto um exemplo muito mais recente e específico, vale a pena acrescentar que as Dixie Chicks utilizaram uma variação do I-V-vi-IV do loop de acordes de Yes we can para acompanhar sua determinação de desafiar as ameaças pessoais que resultaram do fato da banda expressar a vergonha que sentiu pelo fato do ex-presidente norte-americano George Bush ser do mesmo estado natal que elas, o Texas. ${ }^{37}$ Nas palavras de Obama, foi um tempo para mudanças e, mesmo, nas palavras de Dylan, os tempos são, espera-se, de "mudanças prá valer" ("a-changing for real").

Embora este artigo já passe de 8.000 palavras, ainda há muito mais a ser dito sobre a música do vídeo da eleição de Obama e suas conotações. Pode-se argumentar, por exemplo, que o caráter antêmico do IOCM I-V-vi-IV não seja de grande importância para Yes we can e para sua letra, que é quase totalmente falada. Mas este argumento se esvazia em pelo menos um ponto: quais gravações consistindo de frases curtas chamativas apresentadas por diversos artistas, um depois do outro, formando uma série de conclamações, existem no gênero das canções pop reconhecidamente desde, pelo menos, Do They know it's Christmas? da BAND AID (1984). E canções nesta forma - que chamo de charity stringalong (canções de solidariedade com solos de cantores) -, invariavelmente envolvendo uma chamada de participação em uma causa nobre. ${ }^{38}$ Este cantar ou declamar consecutivamente, ao invés de simultaneamente é simplesmente uma outra maneira de, musicalmente, apresentar um sentido de comunidade, que se pode comparar a um salmo ou hino. Yes we can combina, por assim dizer, o universo harmônico comunitário progressista da revista Sing out! ${ }^{39}$, com um tipo de comunidade beneficente e participativa em prol de uma causa humanitária.

Os acordes de Yes we can também se referem a outras tradições da música popular anglófona, como a banda de rock formada por quatro homens (por exemplo, os Beatles, a primeira formação do Radiohead etc.), country-rock e folk-rock (por exemplo, The Band) e soul (por exemplo, Otis Redding). Além disso, Yes we can acrescenta o rap e a pregação afro-americana àquela mistura de estilos, fundindo-os em um único produto. Esta fusão certamente parece se alinhar com os objetivos de unificação e colaboração de Obama. Entretanto, todas essas questões - a inclusão musical de expressões da comunidade, o papel do rap e da pregação religiosa em Yes we can, e sua relação com o contexto político no qual o vídeo foi produzido e utilizado - estão, infelizmente, fora do escopo deste artigo.

\section{Glossário:}

Para uma lista completa de termos e abreviaturas da análise musemática, veja www.tagg.org/articles/ptgloss.html Para uma lista de termos e abreviaturas de harmonia veja p.27-30 do Tagg's Harmony Handout em www.abretagg. org/articles/xpdfs/harmonyhandout.pdf

Acordes vai-e-vem (chord shuttle): neologismo criado por Phillip Tagg em 1993 para descrever a oscilação entre dois acordes, por exemplo, entre as tríades de Si. Menor e Sol Maior no início da Marche funèbre de Chopin, também conhecido como "pêndulo eólio" (BJÖRNBERG, 1989).

\section{Campo Paramusical de Conotação: veja PMFC.}

Comparação interobjetiva (Interobjective comparison): Neologismo criado por Phillip Tagg em 1979 para descrever a comparação musical de intertextos de um ou mais elementos estruturais de uma obra musical com outra.

Estésico: Do francês esthésique (Molino, via Nattiez), é um adjetivo relacionado à aesthesis, ou seja, à percepção da música, ao invés da produção/construção/criação/realização musical. Basicamente, o mesmo que recepcional e o oposto de construcional ou poïético. Na música, busca descrever um elemento da estrutura do ponto de vista de suas qualidades conotativas percebidas, ao invés de sua construção, por exemplo, "delicado", "som de detetive", "allegro" ao invés de "con sordino", "acorde menor com sétima maior", "quarta aumentada", "pentatonicismo" etc.

Harmonia de terças (tertial harmony): Neologismo criado por Phillip Tagg em 1998 para descrever harmonias baseadas na superposição de terças que se entrelaçam (por exemplo, triades comuns, acordes de sétima, acordes de nona etc.), ao contrário da harmonia quartal, em que há a superposição de quartas.

IOCM: Abreviatura de Material de Comparação Interobjetiva (Interobjective Comparison Material), um neologismo criado por Phillip Tagg em 1979 para descrever intertextos musicais, ou seja, trechos de outras obras musicais nos quais pode se demonstrar semelhança com a obra musical que é objeto de análise.

Material de Comparação Interobjetiva: veja IOCM.

Musema: Menor unidade de significado musical. Para o conceito original, veja o artigo de Charles Seeger On the moods of a musical logic no Journal of the American Musicological Society, v.13, p.224-261 (SEEGER, 1960); re-publicado no livro Studies in Musicology 1935-1975 (Berkeley: University of California Press, 1977, p.64-88; musema é definido na p.76).

Paramusical: Qualidade de um elemento semiologicamente relacionado a um discurso musical específico sem ser estruturalmente intrínseco àquele discurso. Neologismo criado por Phillip Tagg em 1983 que significa literalmente "ao lado da música". 
PMFC: Abreviatura de Campo Paramusical de Conotação (Paramusical Field of Connotation), um neologismo criado por Phillip Tagg em 1991 para descrever um campo semântico conotativamente identificável que se relaciona com estruturas musicais (ou um conjunto delas). De 1979 a 1990, foi denominando de EMFA (Extramusical Field of Comparison).

Poïético: Do francês poïétique (Molino, via Nattiez), é um adjetivo relacionado à poïesis, ou seja, o fazer musical, ou invés da percepção musical. Basicamente, o mesmo que construcional e o oposto de estésico ou recepcional. $\mathrm{Na}$ música, busca descrever um elemento da estrutura musical do ponto de vista de sua construção, ao invés de suas qualidades conotativas percebidas, por exemplo, "con sordino", "acorde menor com sétima maior", "quarta aumentada", "pentatonicismo" ao invés de "delicado", "som de detetive", "allegro" etc.

Turnaround: Sequência repetida de acordes, geralmente em número de três ou quatro, ocupando uma frase de dois a quarto compassos, por exemplo, a sequência de acompanhamento I-vi-ii/IV-V, também conhecida como vamp

(termo usado, por exemplo, na frase "vamp till ready").

\section{Referências de textos:}

BJÖRNBERG, Alf. On aeolian harmony in contemporary popular music. Org. Göteborg. IASPM - Nordic Branch Working Papers, no. DK 1. 1989 (também disponivel online em www.tagg.org/others/bjbgeol.html) (Acesso em 18 de março, 2009). HARALAMBOS, Michael. Right on: from blues to soul in black America. London: Eddison Press: 1974.

MOORE, Allan F. Patterns of harmony. Popular Music, v.11, n.1, 1992. p.73-106.

VEGA, Carlos. Panorama de la música popular argentina. Buenos Aires: Losada: 1944.

TAGG, Philip. Glossary of special terms, abbreviations, neologisms, etc. used in writings by Philip Tagg. www.tagg.org/ articles/ptgloss.html. (Acesso em 19 de outubro de 2009). . Tagg's harmony handout. www.tagg.org/articles/xpdfs/harmonyhandout.pdf . (Acesso em 19 de outubro de 2009).

\section{Referências de áudio:}

ABBA. Hasta mañana. Waterloo. Polar POLS 252. 1974.

ADAMS, William ("Will.i.am"). Yes we can. YouTube. 2008. www.youtube.com/watch?v=jjXyqcx-mYY (Acesso em 2 de fevereiro, 2008; gravado em 31 de janeiro, 2008).

ANDERSSON, Lena. Hej du glada sommar. Polar POS 1175. 1973.

BACH, Johann Sebastian. Air, Orchestral Suite in D Major (BWV 1068), 1731. Leipzig: VEB Deutscher Verlag fur Musik (1973); also on Six Brandenburg concertos and four orchestral suites (Ouverturen). Archiv 423 492-2 (1988).

BAND AID. Do They Know It's Christmas?. FEED 1 [single], 1984.

BEATLES, The. She loves you. Parlophone 5015. 1963. . A Day In the life. Sergeant Pepper's Lonely Hearts Club Band. Parlophone PCS 7027. 1967.

Let it be. Let it be. Apple PCS 7096. 1970.

CLAPTON, Eric. Veja DEREK AND THE DOMINOES. 1970. Nobody knows you when you're down and out (unplugged, 9208) www.ca.youtube.com/watch?v=5aDykZEATzk

(Acesso em 2 de fevereiro de 2009). 1992.

CLINE, Patsy. Crazy. The Sound of Patsy Cline. MCA MUP 316. 1961.

CREEDENCE CLEARWATER REVIVAL. Someday never comes. Mardi Gras. Fantasy 4C062-9339. 1971.

COOPER, Alice. School's out. Warner K56007. 1972.

DANIELS, Charlie. A Few more rednecks. Radio special. Epic 1780. 1989.

DENVER, John. Country roads. Poems, prayers and promises. RCA Victor SF 8219. 1971.

DEREK AND THE DOMINOES. Nobody knows you when you're down and out; Bell Bottom Blues. Derek and the Dominoes. Polydor 2 LP-2625-005. 1970.

DIXIE CHICKS, The. Not ready to make nice; The Long way round. The Long way round. OpenWide/Columbia 82876 80739-2. 2006. DYLAN, Bob. A Hard rain's gonna fall'; Don't think twice, It's all right. The Freewheelin' Bob Dylan. CBS 25AP269. 1963. The Times they are a-changing. CBS 2105. 1964a. . It ain't me, babe. Another side of Bob Dylan. CBS 25AP271. $1964 \mathrm{~b}$. 
Its all over now, Baby Blue. Bringing it all back home. Columbia CS 9128. 1965.

John Wesley Harding; I pity the poor immigrant. John Wesley Harding. CBS 25AP277. 1967.

Lay, lady, lay. Nashville skyline. CBS 25AP278. 1969.

George Jackson. CBS 45516. 1971.

Knockin' on heaven's door. Pat Garrett and Billy The Kid. Columbia KC 32460. 1973.

I shall be released. Before the flood. Island IDBD1. 1974.

ELECTRIC LIGHT ORCHESTRA. Jungle (single com Shine a little love no Lado B). JET 12 144. 1973.

FRANCIS, Connie. Who's sorry now? MGM 12588. 1957.

FREBERG, Stan. The Great pretender. Capitol 45-CL 14571. 1956.

GOLDEN GATE ORCHESTRA. The Charleston. Edison Diamond 51542-R. 1925.

GUTHRIE, WOODY. Oklahoma hills [disco original não encontrado]. 1937.

[All of] You fascists are bound to lose. The Ballad operas: TheMartins and the Coys. Rounder 1819 (2000). 1944a. Hey Lolly Lolly. Legendary Woody Guthrie. Tradition 2058 (197?).1944b.

. This Land is your land. This land is your land. The Asch Recordings, Vol. 1. Smithsonian Folkways 40100 (1960). 1944c. Grand Coulee Dam. Columbia River Collection. Topic TSCD 448 (1988). 1945.

Hard travelin'. The Greatest songs of Woody Guthrie.Vanguard VSD 3536 (1972). 1946.

Two good men. Ballads of Sacco \& Vanzetti. Smithsonian Folkways SF 40060 (1960). 1946-1947.

HAMILTON, George (IV). Abilene. RCA Victor 47-9469. 1963.

HOOLA BANDOOLA BAND. Man måste veta vad man önskar sig. Fri information. MNW 35P. 1972.

JOURNEY. Don't stop believing. Escape. Columbia TC 37408. 1981.

KING, Ben E. Stand by me. Atco 6194.1961.

LENNON, John. Imagine. Apple SAPCOR 10004. 1971.

LENNON, John; THE PLASTIC ONO BAND. Instant karma; Woman Is the nigger of mankind. Shaved fish. Apple PCS 7173. 1975.

LOS CALCHAKIS. La Flûte Indienne. Barclay Panache 920014. 1966.

LYNYRD SKYNYRD. Free bird. Lynyrd Skynyrd. MCA DMCL 1798. 1973.

MARLEY, BOB \& THE WAILERS. No Woman no cry. Island WIP 6244; also No Woman no cry live at The Lyceum, London.

Island 16398 AT (1975). 1974.

PARAVONIAN, Rob. Pachelbel rant. www.youtube.com/watch?v=JdxkVQy70LM (Acesso em 8 de fevereiro de 2009). 2006.

PETER \& GORDON. A World without love. Columbia DB 7225. 1964

PETER PAUL AND MARY. Puff (the Magic Dragon). Warner WEP 601. 1963.

Hangman. The Last thing on my mind. Warner WEP 617. 1965.

PROCOL HARUM. A Whiter Shade Of Pale. Deram DM 126. 1967.

RADIOHEAD. Creep. Parlophone TCR 6078; 1992.

REDDING, Otis. Sitting on the dock of the bay. Stax 169027. 1967.

RÖDA KAPELLET. Revolutionens vagga; Solidaritetssång för Chiles folk. Röda Kapellet. Avanti AVLP 01. 1974. .Lärling: från arbetarhem via 9tp. Party Music/Partimusik. Avanti AVLP 02. 1976.

RUFFIN, David. What becomes of the brokenhearted? Soul (Motown) 35022. 1966.

SAKAMOTO, Kiu. Sukiyaki. Odeon 7-1-3030. 1963.

SMITH, Bessie. Nobody knows you when you're down and out. 78 Columbia 14451-D. 1929.

SPENCER DAVIS GROUP, The. Nobody knows you when you're down and out. Gimme some lovin. United Artists UAL 3587. 1967.

THE BAND. The Weight. Music from Big Pink. Capitol ST 2955. 1968.

Daniel and the sacred harp. Stage fright. Capitol SW 425. 1970.

THE FARM. All together now. Jive ZB 44241. 1990.

THE ONLY ONES. Another girl another planet. CBS 6576. 1978.

THE PLATTERS. The great pretender. Mercury MT 117. 1955.

TWISTED SISTER. We're not going to take it. Stay hungry. Atlantic 7567-80156-2. 1984.

WHITE, BARRY. I can't get enough of your love babe. Pye Int. 7N25661. 1974.

WILL.I.AM. Veja ADAMS, Wiliam. 2008.

WINWOOD, Stevie. Veja SPENCER DAVIS GROUP. 1967.

YOUNG, Neil. Southern Man. After the Gold Rush. Reprise 7599-27243-1. 1970.

\section{Referência de vídeo:}

PECK, Cecília; KOPPLE, Bárbara. Shut up and sing (Cabin Creek Films/Weinstein, 2006). 


\section{Notas}

1. 0 vídeo, que nunca foi oficialmente sancionado pela campanha de Obama, foi disponibilizado online em fevereiro de 2008 e, até julho do mesmo ano, foi assistido mais de 21 milhões de vezes. 0 vídeo é de autoria de "Will.i.am" (nome artístico de William Adams) e foi dirigido por Jesse Dylan, filho de Bob Dylan. Fonte: www.en.wikipedia.org/wiki/Will.i.am (Acesso em 15 de março de 2009).

2. 0 loop de acordes $\|: E m|C-A m:\|\mid\|: E m$ - Em7 - C - Am:\| de Southern man não será discutido neste artigo. É, na verdade, uma variante dos acordes vai-e-vem (shuttle chords) no modo eólio (BJÖRNBERG, 1989).

3. Meus comentários foram enviados à lista da IASPM em 19 de Janeiro de 2009.

4. Estou considerando o tom da peça como Sol Maior (I grau), mesmo que a matriz e a gravação ao final, na verdade, termine em Dó Maior (IV grau).

5. No acorde de Dó Maior no início de Not ready to make nice (2006), as Dixie Chicks utilizam o mesmo efeito de nona adicionada (add9). Veja www. youtube.com/watch?v=IHH8bfPhusM (Acesso em 6 de fevereiro de 2009).

6. Como explica Carlos VEGA (1944, p.160), se referindo à musica nessa tradição, "No hay melodias en mayor y melodias en minor: hay simplemente melodias bimodales" [não há melodias em maior ou menor: há simplesmente melodias bi-modais".

7. La Folia foi uma canção bastante popular no início do século XVI, provavelmente de origem portuguesa, também conhecida como Les folies d'Espagne e que serviu de tema para muitas variações no século XVII.

8. De fato, quando eu estava produzindo uma canção de solidariedade no Chile com nossa banda RÖDA KAPELLET (Solidaritetssång för Chiles folk, 1974), optei, sem refletir o porquê naquela época, pela matriz bVI-bIII-V-i (F-C-E-Am). Todos os músicos envolvidos nesta performance, mais Pedro van der Lee (musicólogo e performer argentino-sueco e tocador de huayño), consideravam a peça em Lá Menor, e não em Dó Maior. As outras canções mencionadas por Orozco apresentam características semelhantes. Polo Margariteño também é bi-modal - G D (B) Em Am B Em - e Rio Manzanares, harmonicamente, segue quase como Quiaquenita-G C E Am (bVII-III-V-i). A versão de Elida Nuñes de Uruchaqina, referida por Orozco, é melodicamente bi-modal, mas na sua performance, não se observa nenhuma mudança de campo harmônico. Há, sim, uma espécie de fluxo permanente entre Lá Menor e Dó Maior. Sobre o comentário de VEGA (1944) a respeito de bi-modalidade, veja a nota anterior no presente artigo.

9. A mudança de Si Maior para Mi Menor pode ser um tipo de progressão mais direcional, com função dominante (como um tipo de cadência interrompida), mas ocorre tão claramente no meio da sequência que apresenta mais o caráter de uma progressão tonal temporária do que de uma finalização.

10. Por exemplo, comparando-se a sequência C G D A E (plagal) de Jimi Hendrix com a sequência (B) E A D G (função dominante) de Sweet Georgia Brown. 0 jazz modal e o free jazz estabeleceram outras regras tonais, mas quase todos os outros tipo $\mathrm{s}$ de jazz, inclusive o bebop, se baseiam claramente na direcionalidade V-I e não IV-I.

11. As DIXIE CHICKS, por exemplo, terminam ambas Not ready to make nice e Taking the long way round (2006) com V-IV[-I], uma sequência mais idiomática do que V-I. 0 modo jônico e o passo harmônico V-I aparecem em alguns tipos de música country, mas sua ausência também acontece. Esta característica tonal pode ser derivada de sua preponderância relativa, dentro das músicas tradicionais afro-britânico-americanas, em modos que apresentam a $7^{\text {a }}$ maior a partir da tônica.

12. Sol Maior é uma das tonalidades preferidas de DYLAN. As seguintes canções são também em Sol Maior, embora sejam articuladas de maneira diferente do que acontece em The Times they are a-changing ou Yes we can: I pity the poor immigrant (em 3/4, 1968), I shall be released (com swing), Lay, lady, lay (com órgão e violão de aço, 1969), Don't think twice (com palhetadas sistemáticas, 1963) e It's all over now Baby Blue (Sol maior, mas com uso do capotraste preso no braço do violão, 1965).

13. 0 acorde da tônica Sol tocado na primeira posição marca o início de outras canções de GUTHRIE, como All you fascists are bound to lose e Hey Lolly Lolly (1944). Mesmo a sempre popular This land is your land (1944) de Guthrie, que foi cantada nas festividades de inauguração da campanha de Obama, começa com um acorde de Sol Maior com cordas soltas, embora a canção seja m Ré Maior com o loop de acordes $\|: G|D| A \mid D:\|$.

14. Por exemplo, School's out (COOPER, 1972), A Few more rednecks (DANIELS, 1989), I Can't get enough of your love babe (WHITE, 1974).

15. Os acordes mais fáceis de se tocar no violão, na primeira posição, são Mi Maior, Mi Menor, Sol Maior, Lá Maior, Lá Menor, Dó Maior, Ré Maior e Ré Menor. Não tive qualquer instrução no violão, mas posso produzir esses oito acordes sem dificuldade. Posso mesmo, geralmente com alguns milisegundos de atraso, fazer acordes com pestana como aquele Si Maior de Yes we can. Não consigo lembrar de uma única "canção de protesto" popular dentro das tradições do folk ou folk rock na língua inglesa que não esteja em uma daquelas oito tonalidades. A tonalidade menos comum seria Ré Menor, enquanto que, certamente, Sol Maior e Ré Maior estão entre as tonalidades mais comuns neste tipo de música.

16. Veja também as versões de CLAPTON $(1971,1992)$ e WINWOOD (1967).

17. Seria interessante incluir neste estudo a progressão I-III-IV que ocorre na sequência ao final de Imagine de John Lennon (1971): IV-V-I-III-IV-V-I. Com a letra, temos: [IV] "You may [V] say I'm a [I] dreamer [III] but I'm [IV] not the only [I] one; [IV] I hope some [V] day you'll [I] join us [III IV] and the [V] world will [I] live as one" \{traduzindo: [IV] "Você pode [V] dizer que sou um [I] sonhador [III] mas não [IV] sou o [I] único; [IV] espero que algum [V] dia você se [I] junte a nós [III IV] e aí o [V] mundo [I] viverá como um só]. Infelizmente, tive de excluir esta referência porque o seu III grau não é um passo harmônico inicial e nem é seguido pelo vi grau.

18. 0 termo lo-fi (low-fidelity, ou "baixa fidelidade") foi criado por Murray Schafer como antônimo de hi-fi (high-fidelity).

19. Veja a paródia de Stan FREBERG (1956) da música The Great pretender dos THE PLATTERS (1955).

20. Os acordes de Abilene são $\mathrm{G}|\mathrm{B}| \mathrm{C}|\mathrm{G}| \mathrm{A}|\mathrm{D}| \mathrm{G} \mathrm{C} \mid \mathrm{G}$ [D]| (com swing 4/4 rápido), enquanto que os de Crazy são G|B7|Em|Em|D |D7 |G $\mid \mathrm{G}$ [D]| (balada

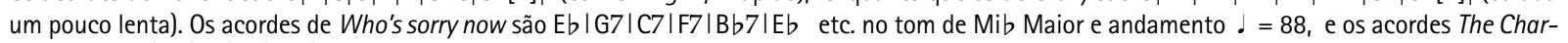
leston são $\mathrm{Bb}|\mathrm{D} 7| \mathrm{G} 7|\mathrm{C} 7| \mathrm{F} 7 \mid \mathrm{B} b$ no tom de Sib Maior e andamento $\cdot=96$.

21. Por exemplo, na gravação de CLAPTON (1972), o andamento é. . $=56$.

22. Note a distinção entre os acordes vai-e-vem (que BJÖRNBERG,1989, chama de pendulum) e o loop de acordes. No passo harmônico vai-e-vem, o acordes vão e depois voltam, mas no loop, os acordes giram ao redor. São necessários três pontos pelo menos para se criar uma forma tri-dimensional. Quanto maior o número de ângulos em uma forma bi-dimensional, mais ela se parecerá com o circulo. 0 diamante que se forma no campo de baseball norte-americano tem quatro ângulos (as "bases"), o que também acontece na área do pitch do jogo inglês rounders. Pode-se caminhar ao redor de um quarteirão completamente retangular. Mas não se caminha ao redor de uma linha reta entre dois pontos, não pelo menos dentro da física de Newton. Ocorre o mesmo com as sequências de acordes. Incidentalmente, Sitting on the dock of the bay também contém os sons de gaivotas na praia obrigatórios, além do barulho das ondas do mar.

23. 0 contexto desta frase na letra de Yes we can é o seguinte: "Yes we can'. It was sung by immigrants as they struck out from distant shores and pioneers who pushed westward against an unforgiving wildeness. 'Yes we can' ". [" 'Sim, nós podemos", cantaram os imigrantes, quando se lançaram de praias distantes, assim como os pioneiros que se embrenharam no oeste contra a natureza inóspita. 'Sim, nós podemos' ".]

24. Quando digo "one five oompah" ["I-V um-pá"], quero dizer a levada do contrabaixo em que "oom" são semínimas pontuadas leves no grave nos tempos 1 e 3, e "pah" são semicolcheias pesadas no registro médio. Para cada acorde, o baixo toca primeiro a fundamental do acorde da cifra e, depois, a quinta em relação àquela nota. Por exemplo, Mi e Si para o acorde de Mi Maior; Sol \# e Ré \# para o acorde Sol \#, Dó\# e Sol\# para o acorde de Dó\# etc. Algumas vezes, a ordem pode ser inversa quando for o acorde do V grau. Por exemplo, Fá\# e Si para o acorde de Si Maior (V) no tom de Mi Maior (I). 
25. A sequência de acordes nos 12 compassos dos versos de $A$ World without love é a seguinte: $\|: \mathrm{E}|\mathrm{G} \#| \mathrm{CHm}|\mathrm{C \# m}| \mathrm{E}|\mathrm{Am}| \mathrm{E}|\mathrm{E}| \mathrm{F} \# \mathrm{~m}|\mathrm{~B}| \mathrm{E}|| 1^{\text {a }}$ casa: C B turnaround :\| 2a casa: $E$... seguindo até a ponte de 8 compassos ou até o final|. A instrumentação da canção consiste de: (1); os pesadamente pontuados "one-five oompahs" de Paul McCartney; (2) uma bateria simples e discreta; (3) uma batida simples do violão; (4) um órgão Vox acompanhando com string pads praticamente inaudiveis junto com a melodia do verso no break instrumental. A linha vocal é cantada por vozes masculinas jovens de maneira lírica e simples.

26. 39\% da canção Creep, que dura 4:00, corresponde a 1:34. A gritaria e o overdrive ocorrem em dois pontos desta gravação: 1:02 -1:24 (22") e 2:06-3:08 (1:02").

27. A canção Creep é única, dentro do conhecimento que tenho sobre outras canções que se baseiam na sequencia do loop I-III-IV-iv. Baseio esta interpretação de dramática desesperança não tanto na letra da canção, embora seu conteúdo contenha bastante drama e desesperança, mas na harmonia, como é comum no tipo de análise musical exagerada que os alunos geralmente apresentam, geralmente com respostas do tipo alienado, com raiva, sem esperança, desesperado, cínico etc. Experimente substituir o acorde de Dó Menor por Ré Maior ou Ré Menor ou Fá Maior.

28. Além de outras inversões de tríades, Brokenhearted contém um acorde de Mi diminuto e apresenta alternâncias bem marcadas para o campo de Dó Maior-Lá Menor para depois voltar a Sib Maior-Sol Menor.

29. Na verdade, Sukiyaki começa com acordes vai-e-vem plagais (I-IV-I no tom de Sol Maior) mas, antes, progride harmonicamente para I-iii-vi-V no compasso 5 do verso.

30. A progressão iii-IV em Baby Blue ocorre mais ao final de cada verso (em "Look out, the saints are coming through" ["Cuidado, os santos estão passando" no verso 1]. 0 iii vi reaparece logo antes do rallentando final ao final de cada verso de I pity the poor immigrant com Joan Baez no disco $A$ Hard Rain concert, 1976).

31. 0 tipo de letra contando histórias que se observa em Hangman, The Weight e I pity the poor immigrant de Dylan também ocorre em outra canção bem conhecida que utiliza a partida harmônica I-iii [-vi] em andamento andante: A Day In the life (1967: "I read the news today" ["Leio as notícias de hoje"], "A crowd of people stood and stared" ["Uma multidão de pessoas parou e encarou"], etc.) dos Beatles. Sem qualquer consciência dessa conexão, nossa banda também utilizou este I-iii[-IV] por razões narrativas semelhantes em Revolutionens vagga (RÖDA KAPELLET, 1974).

32. O Ré e o Fá\# do acorde de Ré Maior no tom de Sol Maior são ambos adjacentes à fundamental da tônica de Mi Menor.

33. Para um hilariante pot-pourri de canções de derivadas do Canon de Pachelbel, veja PARAVONIAN (2006).

34. Vale a pena mencionar que esta canção aparece no ". . álbum Spartacus, o qual tem sido conectado. . . com temas favoritos da banda [The Farm], tais como socialismo, fraternidade e futebol americano" (artigo All together now da Wikipedia (Acesso em 17 de março de 2009).

35. Voltando a falar, pela última vez, do repertório político de esquerda da banda de rock da qual fui membro de 1972 a 1976, talvez valha a pena comentar que utilizamos o loop I-V-vi-IV em Sol Maior (G - D - Em - C) para acompanhar as seções narrativas da montagem de 10 minutos de Lärling (RÖDA KAPELLET, 1976). A letra se refere ao tratamento injusto recebido por aprendizes na indústria e sua determinação de mudanças para melhorar de vida.

36. Don't stop believing (1981) de JOURNEY tem um andamento mais moderado $(\cdot=122)$ do que as faixas de Twisted Sister e Only Ones, e repete o loop I-V-vi-IV durante os versos. Mas, suas quatro semínimas duras, amplificadas no piano e arpejos de semicolcheias pseudo-clássicos na guitarra elétrica, revelam uma instrumentação muito diferente de Yes we can. Mesmo assim, a canção tem algum valor antêmico, com sua letra que clama alguém a não desistir ("Não pare de acreditar"). Um outro exemplo de rock antêmico com I-V-vi-IV em Sol Maior é Free bird de LYNYRD SKYNYRD $(1973,=120)$. Entretanto, esta sequência harmônica faz parte de um período de 8 compassos - $\|:$ I |V|vi|vi ] IV|IV|V|V :\| com o grau IV no compasso 5 iniciando uma segunda frase. Mais apropriada, bastante antêmica e politicamente progressista é a icônica canção sueca Man måste veta vad man önskar sig (1972, $\|: D|A| B m \mid G:\| ; \quad \cdot=120)$ da banda progressiva sueca HOOLA BANDOOLA. Entretanto, assim como ocorre com as referências de RÖDA KAPELLET (notas de fim 7, 29, 33), mesmo com raizes estilisticas na tradição pop/rock anglo americana, a letra é em sueco, e não em inglês.

37. A história completa do incidente no teatro $\mathrm{O}_{2}$ Shepherd's Bush Empire em Londres, em 2003, quando a cantora Natalie Maines das Dixie Chicks expressou sua vergonha de ter nascido no mesmo estado que o presidente George Bush e suas consequências para aquelas três heróicas musicistas jovens do Texas é contada no tocante documentário Shut up and sing (PECK e KOPPLE, 2006).

38. Alguns exemplos destes grupos são Artists united against apartheid (1985), os suecos Svensk rock mot apartheid (1985), Hear'n aid (1986) e Disco aid (1986). 0 verbo string along, de acordo com o Oxford Concise English Dictionary (1995), é uma expressão coloquial que significa "estar em companhia de". Singalong, de acordo com o mesmo dicionário, significa "uma canção que alguém pode cantar junto" ou "uma ocasião de canto comunitário". Se várias pessoas cantam ou falam, uma de cada vez e sucessivamente durante uma canção, elas certamente estão em companhia umas com as outras (e também com a canção), mas elas o fazem consecutivamente e não simultaneamente: daí o termo stringalong.

39 Entre os fundadores da revista Sing Out! estão Pete Seeger, Woody Guthrie, Paul Robeson, Alan Lomax e Irwin Silber. Para uma descrição e história da revista, veja www.singout.org/sohistry.html (Acesso em 18 de março, 2009)

Philip Tagg é Professor de Musicologia na Faculté de Musique da Université de Montréal (Canadá). Co-fundador da International Association for the study of Popular Music (IASPM) e mentor da Encyclopedia of Popular Music of the World (EPMOW), publicou dezenas de artigos nos mais prestigiosos periódicos. Foi professor do Institute of Popular Music da University of Liverpool (Inglaterra), onde orientou mestrandos e doutorandos e desenvolveu cursos de musicologia, análise, harmonia e semiologia relacionados à música popular. Trabalhou também na University of Göteborg (Suécia) e Swedish Council for Research in the Humanities and Social Sciences (Suécia). É organista erudito e tecladista em bandas de rock e pop, entre elas Röda Kapellet. Como compositor, escreveu obras corais e canções populares. É autor e colaborador de diversos programas de rádio educacionais relacionados à música popular. Recebeu diversos prêmios nas áreas de composição, ensino e pesquisa. Seu site www.tagg.org é um dos sites de musicologia e etnomusicologia da música popular mais visitados em todo o mundo, no qual dispobiniliza gratuitamente significativa parte de sua extensa obra didática e de pesquisa.

Fausto Borém é Professor Titular da Escola de Música da Universidade Federal de Minas Gerais (UFMG), onde criou o Mestrado e a Revista Per Musi. É pesquisador do CNPq desde 1994 e seus resultados de pesquisa incluem um livro, três capítulos de livro, dezenas de artigos sobre práticas de performance e suas interfaces (composição, análise, musicologia, etnomusicologia da música popular e educação musical) em periódicos nacionais e internacionais, dezenas de edições de partituras e recitais nos principais eventos nacionais e internacionais de contrabaixo. Recebeu diversos prêmios no Brasil e no exterior como solista, teórico, compositor e professor. Acompanhou músicos eruditos como Yo-Yo Ma, Midori, Menahen Pressler, Yoel Levi, Arnaldo Cohen e músicos populares como Hermeto Pascoal, Egberto Gismonti, Henry Mancini, Bill Mays, Kristin Korb, Grupo UAKTI, Toninho Horta, Juarez Moreira, Tavinho Moura, Roberto Corrêa, Túlio Mourão e Fabiano Araújo Costa. 